\title{
UNA VERSIÓN ALJAMIADA SOBRE JOB
}

Por

MARÍA JOSÉ HERMOSILLA

Presento la transcripción de la versión aljamiada de Corán 38, 41-44, según el ms. $47 \mathrm{~J}(1)$, cuyo comentario constituye un breve relato sobre el bíblico Job (2).

Esta versión aljamiada es la traducción literal de su original árabe, que he identificado (3). Se trata del Mutjașar de Ibn Abī Zamanīn al-llbīīi (m. 399/1009) (4) sobre el Tafsïr de Yahyà b. Salām al-Bașrī (m. 200/815) (5), uno de los primeros comentarios coránicos (6), conservado y utilizado por los moriscos, a juzgar por los manus-

(1) Ocupa los folios 10a, línea 2 y $11 b$ hasta la línea 8. Cf. J. RIBERA y M. ASÍN, Manuscritos árabes y aljamiados de la Biblioteca de la Junta (Madrid, 1912), p. 177; M. JOSÉ HERMOSILLA, "Corán 102, según el ms. 47 J», Anuario de Filología, 11-12 (1985-1986), pp. 36-43; "Otra versión aljamiada de Corán 90 (Ms. 47 J)», Homenaje al profesor Dario Cabanelas Rodriguez en su LXX aniversario (Granada, 1987), I, pp. 19-27; A. VESPERTINO, "Una aproximación a la datación de los manuscritos aljamiado-moriscos", Estudios Románicos, 5 (1987-88-89); Homenaje al profesor Luis Rubio, II, p. 1.428 y nota 92.

(2) Cf. Corán 6,84 y 21,83-84. Para Job en el Islam cf. "Ayyüb» en E/2, 1, p. 819 (A. JEFFERY); D. SIDERSKY, Les origines des légendes musulmanes dans le Coran et dans les vies des Prophétes (Paris, 1933), pp. 69-72; CONCEPCIÓN CASTILLO, "Job en la leyenda musulmana. Estudio comparado", La Ciudad de Dios, CXCV, I (1982), pp. 115-130. Un bello relato aljamiado sobre Job ha sido publicado por A. VESPERTINO en Leyendas aljamiadas y moriscas sobre personajes biblicos (Madrid, 1983), pp. 272-299.

(3) La identificación ha sido posible a partir de la Tesis Doctoral de TERESA LOSADA, Estudios sobre Coranes aljamiados (Barcelona, 1975), que edita las 6 primeras azoras en versión aljamiada del Mujtașar, según el ms. $51 \mathrm{~J}$ y que he podido consultar por deferencia de la autora. J. VERNET ha subrayado la importancia del Tafsit de Yahyà b. Saläm, cf. «Le Tafsir au service de la polémique antimsulmane», Studia islamica XXXXII (1970), pp. 305-309; "Apostillas a las traducciones moriscas de El Corán", Studi in onore di Francesco Gabrieli nel suo ottantesimo compleanno (Roma, 1984), pp. 843-846.

(4) Abū (Abd Allāh Muhammad ibn Abt Zamanīn al-Murri al-Ilbirt, cf. F. SEZGIN, Geschichte der arabischen Schriftums (=GAS) (Leiden, 1964 y ss.), I, p. 46.

(5) Cf. SEZGIN, GAS, I, p. 39.

(6) Cf. SEZGIN, GAS, I, p. 323; LOSADA, Estudios..., pp. 22-23; VERNET, «Apostillas...”, p. 843. 
critos aljamiados conocidos (7) y las citas del Obispo de Barcelona, Martín García (8).

El interés de nuestro texto radicaría, precisamente, en la antigüedad de su original árabe, que pone de relieve una vez más el conservadurismo de la literatura religiosa aljamiado-morisca (9).

Sigo, aunque con variantes, el sistema de transcripción de la profesora María José Fernández en su Tesis Doctoral, Libro de los Castigos (Ms. aljamiado n ${ }^{\circ} 8$ de la Biblioteca de la Junta) (Oviedo, 1987), pp. 5-8, que tengo en fotocopia por amable deferencia de la autora. En cuanto a las vocales anaptíticas y consonantes epentéticas, he tenido en cuenta el criterio de María Jesús Viguera en «Un cuaderno aljamiado de deudas. Medinaceli, siglo XVI (Ms. Junta n. ${ }^{\circ}$ XXXVII-8)», Homenaje a D. José María Lacarra de Miguel en su jubilación del profesorado (Zaragoza, 1977), pp. 229-244.

[10a] 38,41: "Y lee sobr'ellos el fecho de nuestro siervo Ayüb cuando rogó a su Señor i dixo: "Ya me a tentado el ș̣aytān con trebacho y al-'adab".

Dixo al-Hasan (10) que Iblis dixo: "¡Ya Señor!, ea si ay en tus siervos un siervo que, si me das a mí poder sobr'él, se defienda de mi". Dixo: "Sí, mi siervo Ayüb". I diole Allah poder sobr'él, que hiziese en él todo lo que pudiese en hazerlo errar. I prençipió de benir a él con muchas tentaçiones i engaños y él lo veía con su vista i no pudo ser poderoso en él en ninguna cosa. Pues cuando se defendió d'él díxo el aššaytän: "¡Ya Señor!, él se a defendido de mí, pues dame poder sobre sus algos. I prençipió a destruir sus algos, uno depués del otro y atomóse a venir a él y él lo veía por sus ochos". I dizele: "jYā Ayūb!, ya es destruido tu algo d'esta i d'esta manera". I dize Ayūb: "Las loores son ada Allah por ello. Señor Allah, tú me lo diste, tú lo as tomado de mí, i, si hazes fincar mi persona, darte e las loores sobre tu albalä". I hizo aquello hata que fue destruido todo su algo. I dixo Iblïs: "¡Ya Señor!, Ayüb no se acura de su algo, pues dame poder sobre su cuerpo" [10b]. I diole poder sobre su cuerpo Allah y estuvo siete años i meses hata que se caían de su cuerpo los gusanos que se lo comían.

Dixo al-Hasan (11): "Llegóme que los gusanos se caian de su cuerpo i los volvía a su lugar y dezía: Comed de lo que os a dado arrizqi Allah". Dixo al-Hasan: "I ruegó a Su Señor i dixo: ¡Ya Señor!, ame tentado el aššaytān con trebacho y al-

(7) El citado ms. 51 y el $52 \mathrm{~J}$ que parece otra copia de lo mismo. LOSADA identificó pasajes del Mujtașar en el ms. $18 \mathrm{~J}$, publicado por J. VERNET y C. LÓPEZ LILLO, «Un manuscrito morisco del Corán», BRÄBLB, XXXV (1973-1974), pp. 185-255, en Estudios..., pp. 73-75. Cf. también MARÍA JOSE HERMOSILLA en Ios artículos citados.

(8) Cf. J. RIBERA, La polémica cristiano-musulmana en los sermones del Maestro Inquisidor Don Martin Garcia (Barcelona, 1967), pp. 15, 16, 41.

(9) Cf. J. VERNET, "T raducciones moriscas de "El Corän"», Der Orient in der Forschung. Festchrift fur Otto Spies (Wiesbaden, 1967), pp. 686-705; «La exégesis musulmana tradicional en los coranes aljamiados», Actas del Coloquio Internacional sobre Literatura Aljamiada y Morisca. Oviedo, 1972 (Madrid, 1978), pp. 123-145; A. VESPERTINO, «Literatura aljamiada, literatura islámica», Littérature et double culture/Literatura y doble cultura. Actas Noesis (Teruel, 1990), pp. 133 y ss.

(10) Se refiere a Abü Sałid al-Hasan al-BașrT b. al-Yasār (m. 110/728), teólogo y tradicionista. Cf. SEZGIN, GAS, I, p. 591 .

(11) Sic en el ms. $47 \mathrm{~J}$, pero los mss. árabes del Mujtașar, n. ${ }^{\circ} 34$ de la Biblioteca de al-Qarawiyyinn de Fez y n. ${ }^{\circ}$ 820 Add 19490 del British Museum, pág. 295 y fol. 174b, respectivamente, escriben «YaPhyà. 
'adab". Quiere dezir: en su cuerpo. Y en otra aleá dize: "Ame tentado el mal i tú eres el más piadoso de los piadosos" (12).

Díxo: "Y reveló Allah a él: 42-Fiere (en la tierra) con tus piedes (que) aqueste es bañadero fresco i bebrache".

I firió con sus piedes una ferida i él no se podía levantar i beos con una fuente i bañóse en ella i quitóle Allah la presente de su enfermedad. Depués anduvo sobre sus piedes cuarenta cobdos. Depués fuele dicho a él: "[Fiere] (13) con tus piedes otra vegada". I firió con ellos otra herida en la tierra i beos con una fuente i bebió d'ella i quitóle Allah a él la intrínseca de su enfermedad. Y volvióle Allah a él su mujer i su compaña i sus hichos i sus algos de vacas i ganados i animales i todo [11a] lo que se le abía destruido ello mesmo. Depués hízole fincar Allah en ella hata que dio a él de su casta conforme a ello. I es su dicho de Allah: 43-" dimos a él su compaña i semejantes que ellos con ellos con piadad nuestra i por exenplo a los del buen juisyo'.

I fueron que murieron en fueras de la muerte aquella que les abía de venir en sus plazos i los revivcó Allah i cunplióles sus plazos: 44-"I toma en tu mano una manada (de juncos) i fiere con ella i no quebrantes tu juramento".

Dixxo al-Hasan que la mujer de Ayūb era que quería obedeser al aššaytān en partida de los fechos i clamaba ad Ayūb en que lo obedeçiese i juró por Allah que, si Allah lo sanaba, que le daría çien açotes. I no puso en voluntad Ayüb con qué se les daría los açotes. Y estaba en aquella reprobación hata que le dio liçençia Allah en la rogaría i cunplió a él la graçia i vino a él la bendiçión de Allah y el gualardón i vino a él la revelaçión de parte de Allah. Y era su mujer muslima i hízole buena compañía ad Ayüb y era que abía a ella [11b] en poder de Allah buena grada. I reveló Allah a él que tomase en su mano una manada de chuncos i que la firiese con ellos una ferida i hizo Ayūb aquello.

Dïxo Muhammad (14) que fue recontado que la mujer de Ayüb dīxo a él: "Si te açercases al aššaytān con degollar una anaga o alguna cosa, sanarías de tu enfermedad". I dīxo Ayūb: "No lo haré, ni aún un puñado de tierra". I por aquello churó en que la açotaría, si Allah lo sanaba.

Nos lo hallamos çufriente i buen siervo i él fue obidiente».

\section{Glosario de voces árabes en el texto aljamiado}

Al-'adāb = ár. lal-'adāb/ : «castigo, pena, tormento».

Albalā = ár. lal-balā'l: «pesar, prueba».

Alea = ár. /al-āya/ : «aleya, versículo».

Anaqa = ár. /al-'anaq/ : «cabrita».

(12) Corán 21,83.

(13) Falta en $47 \mathrm{~J}$.

(14) Se trata de lbn Abt Zamanīn, cf. LOSADA, Estudios..., p. 114. 
Arrizqi = ár. /al-rizq/ : «subsistencia».

Aššaytān = ár. /al-šayțān/ : «el demonio, Satán».

Muslima $=$ är. Imuslimal : «musulmana».

Šaytān = aššaytān. 